\title{
EDUCAÇÃO INFANTIL: O PAPEL DO GESTOR ESCOLAR PARA A PROMOÇÃO DA EDUCAÇÃO INTEGRAL DA CRIANÇA
}

\section{EARLY CHILDHOOD EDUCATION: the role of school manager for the promotion of integral education of the child}

\author{
EDUCACIÓN INFANTIL: el papel del director de la escuela responsable de la pro- \\ moción de la educación integral del niño
}

Maria Lília Imbiriba Sousa Colares
Professora Doutora do PPGE/HISTEDBR/UFOPA da Universidade Federal do Oeste do Pará (UFOPA).
maria.colares@ufopa.edu.br

Francinara Silva Ferreira Mestranda em Educação da Universidade Federal do Oeste do Pará (UFOPA). francinara.sferreira@gmail.com

Clênya Ruth Alves Vasconcelos Mestranda em Educação da Universidade Federal do Oeste do Pará (UFOPA). ruthclenya@gmail.com

Adriana Oliveira dos Santos Siqueira
Mestranda em Educação da Universidade Federal do Oeste do Pará (UFOPA).
adriana.santos@ifpa.edu.br

RESUMO: Este texto traz uma reflexão acerca da educação infantil e do papel do gestor escolar para promover a educação integral da criança. Fundamenta-se em análise bibliográfica, da qual destacam-se os autores Sarmento (2015), Campos (2015), Paro (2015), Palmen (2015), Hora (2010), Valverde (2009) e Pimentel (2007). Depreende-se, por meio das reflexões tecidas acerca das temáticas educação infantil, educação integral e gestão escolar, que a primeira requer um ressignificar, tendo em vista que, as crianças necessitam de condições adequadas para o seu desenvolvimento integral, questão que tem recebido destaque na legislação brasileira, que busca orientar ações no âmbito educacional que primem pela promoção da educação integral. Nesse cenário, a figura do gestor da instituição de educação infantil surge como fator preponderante para a eficácia dessas ações. Assim sendo, o gestor juntamente com a equipe escolar precisam ser os facilitadores da educação integral da criança.

PALAVRAS-CHAVE: Educação infantil. Gestão escolar. Educação integral.

ABSTRACT: This text brings a reflection about early childhood education and school manager's role to promote the integral education of the child. It rests on bibliographical analysis, which include the authors Sarmento (2015), Campos (2015), Paro (2015), Palmen (2015), Hora (2010), Valverde (2009) and Pimentel (2007). It appears through the reflections about the themes woven child education, integral education and school management, which first requires a resign in order that children need adequate conditions for their comprehensive development, an issue that has received prominence in brazilian legislation, which seeks to guide actions under educational press against the promotion of integral education. In this scenario, the figure of the child education institution manager emerges as dominant factor to the effectiveness of these actions. Therefore, the manager along with the school staff need to be facilitators of the integral education of the child.

KEYWORDS: Early childhood education. School management. Integral education.

RESUMEN: Este texto aporta una reflexión sobre la educación infantil y el papel del director de la escuela para promover la educación integral del niño. Se basa en el análisis bibliográfico, que incluyen los autores Sarmento (2015), Campos (2015), Paro (2015), Palmen (2015), Hora (2010), Valverde (2009) y Pimentel (2007). Se deprende a través de las reflexiones producidas sobre los temas educación infantil, educación integral y gestión de la escuela, que requiere primero un a fin de que los niños necesitan de condiciones adecuadas para su desarrollo integral, un tema que ha recibido la prominencia en la legislación brasileña, que pretende orientar acciones en el ámbito educacional que primen por la promoción de la educación integral. En este escenario, la figura del director de la institución de la educación infantil emerge como factor dominante a la eficacia de estas acciones. Por lo tanto, el director junto con el personal de la escuela deben ser facilitadores de la formación integral del niño.

PALABRAS CLAVE: Educación infantil. Gestión de la escuela. Educación integral.

Artigo recebido em setembro de 2016

Aprovado em novembro de 2016

Cad. Pes., São Luís, v. 23, n. 3, set./dez. 2016 
EDUCAÇÃO INFANTIL | Maria Lília Imbiriba Sousa Colares et. al.

\section{1| INTRODUÇÃO}

A educação infantil no Brasil tem firmado-se nos documentos legais que orientam a educação no país, no entanto, ainda precisa passar por um processo de fortalecimento nos espaços escolares. A legislação prevê que a instituição educacional propicie à criança a educação integral, privilegiando seu desenvolvimento integral, nos aspectos físico, psicológico, intelectual e social.

Considera-se, ainda hoje, um desafio promover a educação integral da criança no cotidiano da escola normal, como previsto na Lei de Diretrizes e Bases da Educação (LDB - Lei n 9.394/96). Para isso é de suma importância a efetiva ação de toda a equipe escolar, de maneira que a participação de todos seja privilegiada e que o líder dessa organização do ambiente escolar seja o gestor, que busque promover na instituição uma educação de qualidade.

Assim, neste texto, os pontos discutidos fazem referência à educação integral da criança, destacando como a educação infantil vem sendo ressignificada na legislação brasileira e o papel do gestor da instituição educacional para a promoção do desenvolvimento integral da criança. Pretende-se com essa discussão refletir acerca das temáticas elencadas, bem como sobre sua implicação para o contexto atual.

\section{2 | A RESSIGNIFICAÇÃO DA EDUCAÇÃO INFANTIL}

A educação infantil, dada a sua característica de iniciação no processo de formação dos sujeitos, apresenta-se como uma instância de formação que pressupõe a eminente reformulação de seus velhos ideais pedagógicos consubstanciados em uma prática de escolarização da infância que esteja em sintonia com as necessidades da criança. A Resolução $n^{\circ}$ 05, de 17 de dezembro de 2009 que fixa as Diretrizes Curriculares Nacionais para a educação infantil é um documento legal que já contempla essa reformulação da prática pedagógica na educação infantil. A definição de criança de modo geral é ampliada, levando-se em consideração as especificidades próprias da infância. Deste modo, a criança é definida como:

Sujeito histórico e de direitos que, nas interações, relações e práticas cotidianas que vivencia, constrói sua identidade pessoal e coletiva, brinca, imagina, fantasia, deseja, aprende, observa, experimenta, narra, questiona e constrói sentidos sobre a natureza e a sociedade, produzindo cultura. (BRASIL, 2009, p. 12).

A julgar pela concepção que os documentos legais indicam sobre a infância e criança, novos caminhos e premissas são construídas para a primeira etapa de formação. Em outras palavras, podemos dizer que vêm se configurando um movimento da educação infantil que busca romper com velhos paradigmas e engessam a possibilidade de um real desenvolvimento do ser humano.

O escopo desse movimento orienta-se com base em um novo sentido para a aprendizagem e desenvolvimento na infância, a criança nesse ínterim passa a ser considerada como sujeito histórico, isto significa ter garantido os seus direitos como cidadão, inserido em um contexto sociocultural como qualquer outro cidadão em diferentes fases de desenvolvimento.

Nessa nova concepção a aprendizagem não fica condicionada a exploração dos aspectos cognitivos das crianças como as velhas práticas assim o fazem. Entram em cena, novas parametrizações para a aprendizagem na educação infantil com base na exploração e ampliação de novas habilidades inerentes aos aspectos sociais, culturais e afetivos dos sujeitos. As práticas pedagógicas, deste modo, superam o caráter escolarizante da educação infantil. As Diretrizes Curriculares Nacionais para a educação infantil fazem menção a isso em alguns de seus objetivos: 
EDUCAÇÃO INFANTIL | Maria Lília Imbiriba Sousa Colares et. al.

As práticas pedagógicas que compõem a proposta curricular da Educação Infantil devem ter como eixos norteadores as interações e a brincadeira e garantir experiências que:

- Promovam o conhecimento de si e do mundo por meio da ampliação de experiências sensoriais, expressivas, corporais que possibilitem movimentação ampla, expressão da individualidade e respeito pelos ritmos e desejos da criança;

- Favoreçam a imersão das crianças nas diferentes linguagens e o progressivo domínio por elas de vários gêneros e formas de expressão: gestual, verbal, plástica, dramática e musical;

- Recriem, em contextos significativos para as crianças, relações quantitativas, medidas, formas e orientações espaço temporais;

- Possibilitem situações de aprendizagem mediadas para a elaboração da autonomia das crianças nas ações de cuidado pessoal, auto-organização, saúde e bem-estar;

- Possibilitem vivências éticas e estéticas com outras crianças e grupos culturais, que alarguem seus padrões de referência e de identidades no diálogo e conhecimento da diversidade;

- Incentivem a curiosidade, a exploração, o encantamento, o questionamento, a indagação e o conhecimento das crianças em relação ao mundo físico e social, ao tempo e à natureza;

- Promovam o relacionamento e a interação das crianças com diversificadas manifestações de música, artes plásticas e gráficas, cinema, fotografia, dança, teatro, poesia e literatura;

- Propiciem a interação e o conhecimento pelas crianças das manifestações e tradições culturais brasileiras. (BRASIL, 2009, p. 4).

Depreende-se do exposto novos olhares sobre a infância e o modo como a criança aprende, pois seu processo de aprendizagem e desenvolvimento, que outrora estava sujeito a práticas pedagógicas sustentados na exploração dos aspectos cognitivos, agora é orientado pela exploração da brincadeira e jogos de interação com sentido educativo.

Essa nova concepção de educação infantil hoje é influenciada pelos pensamentos e estudos da teoria de Vygotsky que deram origem a corrente teórica e filosófica chamada histórico-cultural. Tal teoria aporta-se a um processo de desenvolvimento do indivíduo atrelado a estímulos oriundos do meio externo, em outras palavras de sua interação social e cultural com outros sujeitos. Assim, para os autores expoentes da teoria, o indivíduo aprende e se desenvolve quando interage no campo social e cultural, num movimento de estímulo e consequentemente apropriação de conhecimentos e objetos da cultura. Essa corrente diverge do que Piaget defende em sua teoria biológica do desenvolvimento humano, onde expõe que a estruturação dos aspectos biológicos e cognitivos são elementos condicionantes para o desenvolvimento dos sujeitos.

A discussão subsidiada pelos estudos da teoria histórico-cultural aponta para a necessidade da inserção dos jogos e brincadeiras na primeira infância. A defesa da intermediação através do uso de jogos e brincadeiras para levar ao processo de aprendizagem e desenvolvimento da criança é justificada, segundo estudos da própria teoria, na potencialidade que os mesmos detêm, ao estimular e ampliar habilidades cognitivas, físicas emocionais e sociais das crianças. Pimentel (2007, p. 228) afirma:

De acordo com os teóricos da corrente histórico - cultural, o jogo é a atividade principal da criança pré-escolar, ou seja, é o mediador por excelência das principais transformações que definem seu desenvolvimento. Fundamentar a educação infantil na ludicidade significa um saber-fazer reflexivo para que o jogo seja constituinte de zonas de desenvolvimento proximal.

Nessa conjuntura o brincar ganha novo formato no ambiente de atividades da educação infantil, reflexo de debruçamento sobre os estudos, pesquisas, eventos que vêm fomentando esse novo 
EDUCAÇÃO INFANTIL | Maria Lília Imbiriba Sousa Colares et. al.

olhar para o uso de jogos e brincadeiras. De modo geral, dá-se novo sentido às antigas práticas que na escola foram arraigadas ao longo dos tempos. Esse movimento ganha força no enfrentamento do processo que marca a educação infantil, que se reflete no encurtamento da infância em face da intensa demanda por uma formação altamente escolarizante, reflexo do modelo econômico de sociedade que possuímos.

Ressignificar a educação infantil atualmente perpassa pelo entendimento do que é ser criança hoje, como essa criança se desenvolve haja vista as especificidades próprias da faixa etária. Eis o desafio lançado para a organização das creches, pré-escolas e primordialmente para os gestores e professores que cumprem o papel de dar novos rumos ao processo. Nesse sentido, o Plano Nacional de Educação - PNE (2014-2024), traz em sua $1^{\mathrm{a}}$ meta, na estratégia 1.13 a seguinte orientação:

\begin{abstract}
Preservar as especificidades da educação infantil na organização das redes escolares, garantindo o atendimento da criança de zero a cinco anos em estabelecimentos que atendam a parâmetros nacionais de qualidade, e a articulação com a etapa escolar seguinte, visando ao ingresso do (a) aluno(a) de seis anos de idade no ensino fundamental. (BRASIL, 2014, p. 50).
\end{abstract}

Portanto, as políticas públicas para a educação infantil legitimadas através dos documentos legais, como o Estatuto da Criança e do Adolescente - ECA (1990) em seu art. 54; a Lei de Diretrizes e Bases da Educação - LDB de 1996 em seu artigo 4º parágrafos 21, 29, 30, 31 e 62; Lei $n^{\circ}$ 11.274, de 06 de fevereiro de 2006; e Lei $n^{\circ} 11.494$, de 20 de junho de 2007, orientam e dão suporte à educação infantil no sentido de dar subsídios para a efetivação de um projeto de educação para as crianças compreendidas como sujeitos históricos e sociais.

\title{
3 | EDUCAÇÃO INFANTIL, EDUCAÇÃO INTEGRAL E EDUCAÇÃO DE TEMPO INTEGRAL: limites e possibilidades
}

Na sociedade contemporânea, em que as crianças se inserem cada vez mais cedo em outras instituições que não são a família, destaca-se a instituição educacional, onde o atendimento às crianças de 0 a 5 anos ganha ênfase, seja nas legislações que regulamentam a oferta de atendimento a educação infantil, seja nos estudos que vem sendo desenvolvidos a partir da reflexão sobre qual atendimento educacional é mais adequado para essa faixa etária da educação básica.

A Lei de Diretrizes e Bases da Educação Nacional (LDB de 1996) determina a educação infantil como primeira etapa da educação básica, oportunizando às crianças frequentarem instituições de educação infantil desde os primeiros meses de vida. Esta lei prevê ainda, o redimensionamento do caráter de amparo e assistência para o de desenvolvimento integral da criança, que busca a integração entre as dimensões do cuidar e educar através de políticas públicas que contemplem a educação, a saúde e a assistência (VALVERDE, 2009, p. 32).

A temática da educação integral, hodiernamente evidente, não é uma proposta nova. Ela tem sido tratada em diferentes períodos históricos a partir das matrizes ideológicas defendidas nas concepções presentes no cenário educacional brasileiro. Os autores Lima e Almada (2013) destacam as principais concepções de Educação Integral que emergiram no Brasil.

A primeira, defendida na década de 1930 pelo Movimento Integralista, concebe a educação integral baseada na formação da espiritualidade, no nacionalismo, no civismo e na disciplina em uma perspectiva claramente conservadora e autoritária.

A segunda, denominada de concepção anarquista, baseia-se nos ideais libertários e defende que a educação deve ser estética, esportiva, filosófica, profissional e política. E que garanta à classe 
EDUCAÇÃO INFANTIL | Maria Lília Imbiriba Sousa Colares et. al.

trabalhadora uma educação mais completa possível, num patamar que a eleve além da educação da classe capitalista.

A terceira concepção, denominada de pragmática, tem como principal representante John Dewey, cujo pensamento influenciou o educador brasileiro Anísio Teixeira, uma das lideranças do movimento da Escola Nova. O cerne dessa concepção parte da ideia de "experiência", entendida como a própria vida, em que a escola é o lugar das experiências reflexivas, uma micro-sociedade em permanente diálogo com a sociedade maior.

Finalmente, a quarta concepção é a proposta marxista de educação integral, baseada no pensamento de Karl Marx e Friederich Engels. Esta defende uma educação a serviço do homem que rearticule o trabalho manual e a atividade intelectual, devendo voltar-se plenamente a formação integral do homem.

Diante dessas diferentes visões de mundo e de modos de conceber o homem em sua relação com os outros e com a sociedade em que vive, a autora Coelho (2009, p. 90) afirma que:

[...] a educação integral se caracteriza pela busca de uma formação a mais completa possível para o ser humano. Não há hegemonia no tocante ao que se convenciona chamar de "formação completa", ou seja, quais pressupostos teóricos e abordagens metodológicas a constituirão".

As diferentes concepções aqui apresentadas explicitam princípios político-filosóficos que determinam as escolhas, no tocante as políticas educacionais implementadas. A partir desse aporte teórico pode-se estabelecer importantes reflexões sobre a realidade atual da educação infantil, na abordagem da educação integral. Maurício (2015) apresenta duas propostas, uma que denomina de assistencialista, voltada mais para a proteção social, priorizando população e territórios em situação de vulnerabilidade social, afastando-se de uma proposta educacional e a outra sócio-histórica, que se constitui em uma concepção emancipatória e democrática.

O debate se estende quando se insere a temática do tempo escolar como uma possibilidade de melhoria da qualidade da educação, a partir de sua ampliação. Há uma defesa da educação em tempo integral. E então, surge o questionamento: a ampliação do tempo garante uma educação integral?

Não há como negar as questões sociais como resultados do modelo econômico vigente que produz demandas que se estendem a educação, diante da ocupação dos pais que repassam a outras instituições o cuidado aos seus filhos. Contudo, o que Maurício (2015) coloca como caráter inovador para a ampliação da jornada escolar é o preenchimento do tempo com proposta pedagógica integral, a partir da construção de uma identidade própria para a educação infantil como primeira etapa da educação básica. Dessa compreensão decorre que somente a ampliação do tempo não garante uma educação integral, o que pode possibilitá-la é a forma como esse tempo é ocupado, independentemente de ser parcial ou integral.

As razões históricas e econômicas que justificam e consolidam a visão meramente assistencia- lista da organização dos estabelecimentos educativos devem ser questionadas, e aspira-se que a promoção da mudança seja motivada pelo atendimento dos direitos da criança ao usufruto de uma educação de qualidade, sem distinção de origem social, raça, localização geográfica ou qualquer outra diferença.

A educação na infância, portanto, se pautará numa visão da criança cidadã e na perspectiva pedagógica de uma educação na infância fora da "forma escolar", centrada na criança, nas culturas infantis, na ludicidade e criatividade e na ampliação das possibilidades de experiência do mundo (SARMENTO, 2015). 
A compreensão de educação na infância ora descrita exige um repensar sobre as práticas desenvolvidas nesses espaços educativos. Sarmento (2015) apresenta algumas propostas, nessa perspectiva, para a educação na infância em tempo integral:

a) a organização da educação na infância como um campo de possibilidades, em que se recusa os modelos finalizados, os padrões e as rotinas rígidas e toma-se como ponto de partida a realidade social e cultural da criança para a organização da ação pedagógica;

b) pensar as instituições educativas como um lugar de encontro de culturas, o que implica sair do confinamento do espaço tempo em que as crianças estão, abrir a porta das instituições educativas e garantir uma diversidade de experiências, contatos e práticas culturais das crianças, por meio das quais interpretam e simbolizam o mundo;

c) a escola infantil ou jardim de infância é um mundo social de vida das crianças. Nela emergem todas as dimensões que ocupam a vida da criança: o corpo, a condição social, o gênero, a pertença étnica e cultural, sendo o estabelecimento educativo o lugar da afirmação plena dos direitos da criança, não sendo a única responsável por essa tarefa, mas estabelecendo elos com a comunidade socialmente organizada para a construção do bem-estar social dessa criança; d) organizar a escola como uma polis, o que requer a participação das crianças a partir de dispositivos adequados para que estas possam se exprimir sem constrangimentos, em que o compartilhamento de tomadas de decisão com os adultos expressem o espaço político de afirmação dos direitos da criança;

e) a educação infantil é uma educação na cidade. O aprendizado da criança vai além da sala de atividades, pois o aprendizado também ocorre no museu, no centro cultural, no jardim, no parque infantil, no centro de educação e ciência, nos parques urbanos, entre outros.

A realização dessa proposta impõe alguns desafios identificados em pesquisas realizadas por essa autora. Segundo Maurício (2015), tanto professores quanto gestores escolares apontam o espaço físico e a infraestrutura como as dificuldades mais recorrentes para a implementação do tempo integral, pois são fatores que agravam as condições de trabalho e caracterizam a precarização. Para esses profissionais novos espaços e tempos são necessários para a diversificação dos trabalhos.

A realidade da educação de tempo integral na educação infantil, mesmo que ainda não universalizada, está posta. As condições adequadas não se efetivaram e, enquanto isso, os professores e principalmente os gestores se veem diante do desafio de promover condições adequadas para a educação integral da criança.

\section{4 | A GESTÃO DAS INSTITUIÇÕES DE EDUCAÇÃO INFANTIL: pela educação integral das crianças pequenas}

Com a redemocratização da educação no início dos anos de 1980, e com a criação dos documentos legais que regulamentam a educação brasileira - a Constituição Federal de 1988, o Plano Nacional de Educação, a Lei de Diretrizes e bases da Educação de 1996, por meio da Emenda Constitucional - EC no 14, a educação infantil modalidade de ensino que até então não recebia lugar de destaque recebeu merecido reconhecimento, sendo a base dos primeiros passos que a criança dá na educação formal, contudo, ainda hoje existem diversos desafios a serem superados na educação infantil. Nesse contexto, de forma a contribuir com esse intento o gestor da instituição de educação infantil precisa alinhar sua forma de gerir o ambiente, para que se possibilite a criança, por meio da educação o seu desenvolvimento integral. 
EDUCAÇÃO INFANTIL | Maria Lília Imbiriba Sousa Colares et. al.

\begin{abstract}
Diante da atual configuração administrativa e didática da escola básica, que se mantém presa a paradigmas arcaicos, tanto em termos técnicos-científicos quanto em termos sociais e políticos, é preciso propor e levar avante uma verdadeira reformulação do atual padrão de escola, que esteja de acordo com uma concepção de mundo e de educação comprometida com a democracia e a formação integral do ser humano-histórico, e que se fundamente nos avanços da Pedagogia e das ciências e disciplinas que lhe dão subsídios. (PARO, 2015, p. 120).
\end{abstract}

De acordo com a EC n 14/1996 cabe aos municípios o atendimento prioritário ao ensino fundamental e a responsabilidade pela oferta pública da educação infantil. Nesse sentido, os municípios precisam atender às condições de infraestrutura, recursos humanos, bem como a ampliação da oferta de vagas para atendimento às demandas garantidas constitucionalmente.

A partir da LDB/1996 houve a especificação da educação infantil na forma da lei, ou seja, a educação infantil passa a ser ofertada em creches e pré-escolas às crianças de zero a seis anos, de maneira obrigatória. No entanto, a ampliação da oferta de oportunidades educativas, a obrigatoriedade de matrícula e de frequência nas pré-escolas pode provocar distorções na especificidade que caracteriza a educação infantil.

O Plano Nacional de Educação (2014-2024) também traz a orientação da ampliação na oferta de vagas em creches e pré-escolas. Contudo, além de incluir mais crianças na educação infantil, é indispensável que esse atendimento seja feito com qualidade, o que passa necessariamente por uma boa gestão. É importante frisar também a necessidade da criação e manutenção de políticas públicas que contemplem as especificidades da educação infantil, dando o relevo devido a essa primeira etapa da educação básica.

Em meio a esse cenário no que tange a educação infantil, atualmente têm emergido inúmeras discussões sobre o tempo integral nessa modalidade de ensino, pois com ele surgem desafios no ambiente escolar, e os sujeitos responsáveis pelas ações nesse espaço são os protagonistas na ampliação do tempo da criança na instituição.

Destacamos o compromisso que as instituições deverão ter, de forma articulada ao Poder Público, para a efetivação de um trabalho por meio de um projeto político pedagógico que contribua para garantir a promoção de um tempo qualificado, como possibilidade de experiências significativas para as crianças que associe o cuidar ao educar, e não a ampliação da jornada em atendimento exclusivamente à reivindicação familiar e às políticas assistencialistas. (PEIXOTO; SCHUCHTER; ARAÚJO, 2015, p. 130).

Peixoto, Schuchter e Araújo (2015, p. 132) pontuam que "pensar a educação infantil em jornada ampliada, implica garantir condições para se efetivar o desenvolvimento integral da criança em seus aspectos físico, psicológico, intelectual e social", assim como preceitua a LDB/1996,

Art. $29^{\circ}$. A educação infantil, primeira etapa da educação básica, tem como finalidade o desenvolvimento integral da criança até seis anos de idade, em seus aspectos físico, psicológico, intelectual e social, complementando a ação da família e da comunidade. (BRASIL, 1996b, p. 17).

O artigo dá relevo à educação integral da criança que traz desafios ao gestor escolar, que têm o papel de planejar e organizar o funcionamento da instituição responsável pela oferta da educação infantil. "Entre os maiores desafios está a garantia de um tempo qualificado, pois cabe-nos refletir se a ampliação do tempo de permanência na instituição tem significado uma educação integral" (PEIXOTO; SCHUCHTER; ARAÚJO, 2015, p. 144). 
EDUCAÇÃO INFANTIL | Maria Lília Imbiriba Sousa Colares et. al.

O gestor precisa envolver toda a equipe que trabalha diretamente com a criança, uma vez que é o responsável por liderar as ações no ambiente escolar, sendo elas positivas ou negativas, assim sendo, somente com uma boa gestão é possível garantir um bom trabalho educativo com as crianças. Para tanto, faz-se indispensável a participação dos segmentos envolvidos no processo educativo na gestão da instituição educacional, para assim se fazer presente nesse espaço uma gestão com caráter mais democrático.

A gestão democrática não é um caminho pronto. É um processo que se constrói pelo jeito de caminhar. É um processo que não ocorrerá espontaneamente, desenrola-se em uma dinâmica de relações de poder que, por vezes, pode entravar o seu avanço. É necessário que seja provocada, vivida e apreendida por todos que pertencem ao contexto social imediato da organização escolar, sujeitos sociais, construindo a sua história. (HORA, 2000 apud HORA, 2010, p. 93).

Quanto a democracia na gestão da educação infantil, Campos (2015, p. 10) defende que "a gestão democrática não se resume à existência de um conselho de escola na unidade, embora ele seja uma condição importante para efetivá-la". Este configura-se como um instrumento consultivo e deliberativo nas ações desenvolvidas na escola, assim, é entendido como,

Um órgão colegiado escolar que constitui-se em um mecanismo de gestão da escola que tem por objetivo auxiliar na tomada de decisão em todas as suas áreas de atuação, procurando diferentes meios para se alcançar o objetivo de ajudar o estabelecimento de ensino, em todos os seus aspectos, pela participação de modo interativo de pais, professores e funcionários. (LÜCK, 2006, p. 66).

Ou seja, o conselho escolar é um instrumento motivador da gestão democrática na escola, mas para que esta se efetive é preciso a participação ativa de todos os envolvidos no processo educativo, e não apenas que sejam parte constituinte do conselho.

Zabalza e Cerdeirinã (2015, p. 13) pontuam que

É verdade que os líderes, independentemente do seu estilo de gestão, não são capazes de oferecer por si sós uma educação de qualidade. Essa é uma tarefa coletiva que requer a participação de todos (podemos lembrar o dito dos watusi: "para educar uma criança, é necessária toda a tribo"), mas não podemos negar que essa participação depende, em boa parte, da energia e da capacidade para mobilizar dos líderes da instituição. Boa liderança e qualidade institucional estão, pois intrinsecamente ligadas.

Assim,

Gerenciar uma escola infantil supõe organizar e dar vida a esse ecossistema privilegiado que deve ser a escola. Gestores e educadores infantis, como profissionais do desenvolvimento infantil, são os principais promotores da potencialidade formativa dos contextos. Devemos exercer essa tarefa tanto de forma direta quanto por meio do apoio dos pais, de outros profissionais e membros da comunidade local. (ZABALZA; CERDEIRINÃ, 2015, p. 14).

Cabe então aos promotores da aprendizagem da criança, gestores e professores, propiciarem contextos adequados à eficácia nesse processo educativo, de maneira a possibilitarem de fato a educação integral desta.

Para tanto, o gestor deve ser o líder nas ações desenvolvidas na instituição escolar, assim sendo, Martins Filho (2015, p. 38) concebe que "a gestão pode ser compreendida como a orquestração de um grupo que desenvolve o trabalho relacionado a um projeto pedagógico". Enfatiza, 
EDUCAÇÃO INFANTIL | Maria Lília Imbiriba Sousa Colares et. al.

A importância da construção de um projeto coletivo de educação no seio da instituição. O projeto como uma construção coletiva significa um processo que deve encorajar uma dinâmica que desenvolva relações democráticas, colaborativas e participativas entre todos os sujeitos envolvidos. (MARTINS FILHO, 2015, p. 38).

Sônia Kramer (2007 apud MARTINS FILHO, 2015, p. 39) aborda a gestão como um "gesto grande", pois entende, que "a gestão tem a ver exatamente com isso: com os gestos grandes que somos capazes de fazer". Alguns dos "gestos grandes" que precisam estar presentes no contexto da educação infantil são "ouvir, acolher, cuidar de si e do outro, promover a democracia participativa, respeitar, partilhar, colaborar e conviver com presença” (MARTINS FILHO, 2015, p. 40).

Em um contexto educacional em que são imperiosos o cuidado e a educação, vistos como indissociáveis, deve haver um projeto de gestão que direcione o trabalho com as crianças e conduza os profissionais a outros patamares, superando conflitos e confrontos, estabelecendo uma gestão focada tanto na instituição quanto nas esferas externas a ela. Esse é um percurso que objetiva inaugurar compreensões sobre a gestão na educação infantil como um desenho próprio, que contemple as especificidades educacionais dessa faixa etária. (MATINS FILHO, 2015, p. 40).

Tomé (2012 apud MARTINS FILHO, 2015, p. 42) afirma que a gestão de instituições de educação infantil no Brasil encontra-se em processo de construção, destacando que "a integração de creches e pré-escolas aos sistemas de ensino municipais tem seguido a lógica de gestão do ensino fundamental, sobretudo dos anos iniciais, com práticas de escolarização precoce". Nesse sentido, deixa-se de considerar as características próprias da educação infantil, como o brincar, o espaço físico adequado, os materiais necessários ao aprendizado da criança, a rotina, a alimentação, a relação com a família, profissionais da educação com formação correspondente as necessidades dessa modalidade de ensino em consonância com as especificidades da etapa educacional, esse cenário compõe o local do trabalho do gestor escolar que precisa gerir as ações que permeiam a aprendizagem na unidade de educação infantil.

Educar não é apenas explicar a lição ou expor um conteúdo disciplinar, mas propiciar condições para que o educando se faça sujeito de seu aprendizado, levando em conta seu processo de desenvolvimento biopsíquico e social desde o momento em que nasce. (PARO, 2015, p. 49).

No Brasil algumas iniciativas tem sido desenvolvidas no intuito de qualificar a aprendizagem das crianças, por meio de políticas públicas educacionais são criados programas indutores da educação integral, dentre eles, tem recebido destaque nas discussões atuais o Programa Mais Educação, que amplia o tempo de permanência da criança na escola, este tem trazido consigo alguns questionamentos, como: a ampliação do tempo escolar está possibilitando a educação integral da criança?

Nesse contexto, volta-se o olhar para dentro da escola, para observar como está se organizando o ambiente para a ampliação da jornada escolar e promoção da educação integral da criança, além disso, verifica-se o papel dos segmentos desta (gestor, coordenador pedagógico, professor, pais, comunidade escolar em geral) na efetivação das ações dessa proposta de educação.

No que diz respeito a gestão, entre os maiores desafios está a garantia de um tempo qualificado, pois cabe-nos refletir se a ampliação do tempo de permanência na instituição tem significado uma educação integral.

É imprescindível nas instituições de educação infantil a participação de toda a equipe escolar, desde a elaboração do Projeto Político Pedagógico que precisa estar em consonância com o que 
EDUCAÇÃO INFANTIL | Maria Lília Imbiriba Sousa Colares et. al.

se pretende para a educação integral das crianças pequenas.

Outrossim, é importante instigar o saber na criança, o pensar, o refletir, esse caminho corrobora para promoção do desenvolvimento integral dela, e a educação precisa possibilitar isso a criança. Considerando que a aprendizagem gera desenvolvimento, e não o contrário, deve-se motivar experiências as crianças que possibilitarão seu desenvolvimento, permitindo a elas aprendizagens significativas, ligadas a intencionalidade, interesse pela aprendizagem, isso necessita de motivação. Nesse viés deve figurar o gestor que vai gerir a instituição educacional, e os profissionais que nela atuam, buscando privilegiar a participação de todos nas ações no cotidiano escolar, propiciando assim um espaço democrático, para que coletivamente busquem a efetivação da educação integral das crianças.

\section{5 | CONSIDERAÇÕES FINAIS}

Na educação infantil a criança tem o momento de ampliar experiências e registros para posteriormente decodificá-los. Nessa que é a primeira etapa da educação básica, é imprescindível uma liderança preocupada com a qualidade de vida de quem trabalha e convive na escola, desde os educadores e as crianças até as famílias e o entorno em que esta se localiza, nessa missão figura o gestor da escola.

De acordo com Palmen (2015, p. 41-42) "é preciso intensificar a articulação da educação infantil com os conhecimentos da gestão escolar, favorecendo-se a construção de novas ideias e práticas que dialoguem com a realidade das escolas de educação infantil e subsidiem o trabalho de seus gestores".

Nesse viés, concebe-se que o gestor da instituição de educação infantil deve propiciar um ambiente adequado ao desenvolvimento da criança, no entanto, esse trabalho precisa ocorrer coletivamente, por meio da colaboração de todos os segmentos envolvidos no processo educativo. Porém, deve-se articular as ações necessárias a educação infantil à forma como a gestão da escola se desenvolve, de maneira a possibilitar melhorias na realidade da instituição de educação infantil.

Por fim, compreende-se que a gestão da educação infantil constitui um tema crucial na busca por ganhos de qualidade no ensino das crianças pequenas, tendo em vista que, necessitam receber uma base sólida de aprendizagem adequada para desenvolver-se integralmente, e possa permiti-las dar passos mais firmes em sua trajetória escolar, e o gestor juntamente com a equipe escolar precisam ser os facilitadores da educação integral da criança. 
EDUCAÇÃO INFANTIL | Maria Lília Imbiriba Sousa Colares et. al.

\section{Referências}

BRASIL. Constituição (1988). Constituição da República Federativa do Brasil. Brasília, DF: Senado Federal, 1988.

Emenda Constitucional $n^{\circ} 14$, de 12 de setembro de 1996. Modifica os arts. 34, 208, 211 e 212 da Constituição Federal e dá nova redação ao art. 60 do Ato das Disposições constitucionais Transitórias. Diário Oficial da União. Brasília, DF, 13 set. 1996a. Disponível em: <http:// www.planalto.gov.br/ccivil_03/Constituicao/Emendas/ Emc/emc14.htm>. Acesso em: 20 jan. 2016.

Lei n 8.069, de 13 de julho de 1990. Dispõe sobre o Estatuto da Criança e do Adolescente e dá outras providências. Diário Oficial da União. Brasília, DF, 16 jul. 1990. Disponível em: <https://www.planalto.gov.br/ccivil_03/leis/L8069.htm>. Acesso em: 20 jan 2016.

Lei $n^{\circ}$ 9.394, de 20 de dezembro de 1996. Estabelece as diretrizes e bases da educação nacional. Diário Oficial da União. Brasília, DF, 23 dez. 1996b. Disponível em: <http://www.planalto.gov.br/ccivil_03/leis/l9394.htm>. Acesso em: 20 jan. 2016.

. Lei $n^{\circ} 11.274$, de 06 de fevereiro de 2006. Altera a redação dos arts. 29, 30, 32 e 87 da Lei no 9.394, de 20 de dezembro de 1996, que estabelece as diretrizes e bases da educação nacional, dispondo sobre a duração de 9 (nove) anos para o ensino fundamental, com matrícula obrigatória a partir dos 6 (seis) anos de idade. Diário Oficial da União. Brasília, DF, 7 fev. 2006. Disponível em: <http:// www.planalto.gov.br/ccivil_03/_ato2004-2006/2006/lei/ 111274.htm>. Acesso em: 20 jan. 2016.

Lei $n^{\circ} 11.494$, de 20 de junho de 2007. Regulamenta o Fundo de Manutenção e Desenvolvimento da Educação Básica e de Valorização dos Profissionais da Educação - FUNDEB, de que trata o art. 60 do Ato das Disposições Constitucionais Transitórias; altera a Lei no 10.195, de 14 de fevereiro de 2001; revoga dispositivos das Leis nos 9.424, de 24 de dezembro de 1996, 10.880, de 9 de junho de 2004, e 10.845, de 5 de março de 2004; e dá outras providências. Diário Oficial da União. Brasília, DF, 21 jun. 2007. Disponível em: <http://www.planalto.gov.br/ ccivil_03/_ato2007-2010/2007/lei/l11494.htm>. Acesso em: 20 jan. 2016.

Lei $n^{\circ} 13.005$, de 25 de junho de 2014. Aprova o Plano Nacional de Educação - PNE e dá outras providências. Diário Oficial da União. Brasília, DF, 26 jun. 2014. Disponívelem: <http://www.planalto.gov.br/ccivil_03/_ato20112014/2014/lei/l13005.htm>. Acesso em: $2 \overline{5}$ nov. 2015

. Resolução CNE/CEB n 05, de 17 de dezembro de $200 \overline{9}$. Fixa as Diretrizes Curriculares Nacionais para a Educação Infantil. Diário Oficial da União. Brasília, DF, 18 dez. 2009. Seção 1, p. 18. Disponível em: <http://portal. mec.gov.br/index.php?option=com_docman\&view=download\&alias=2298-rceb005-09\&category_slug=dezembro-2009-pdf\&Itemid=30192>. Acesso em: 25 nov. 2015.
CAMPOS, M. M. Gestão na educação infantil. Revista Pátio: Educação Infantil, ano 13, n. 43, abr./jun. 2015.

COELHO, L. M. C. da C. História(s) da educação integral. Em Aberto, Brasília: Inep, v. 22, n. 80, p. 83-96, abr. 2009.

MARTINS FILHO, A. J. A gestão como gesto grande. Revista Pátio: Educação Infantil, ano 13, n. 43, abr./jun. 2015.

HORA, D. L. Gestão educacional democrática. 2. ed. Campinas: Editora Alínea, 2010.

LIMA, F. das C. S.; ALMADA, J. U. P. S. de. Educação integral: concepções, experiências e a sinalização do projeto de lei do Plano Nacional de Educação 2011-2020. In: LIMA, F. das C. S.; LIMA, L. M.; CARDOZO, M. J. P. B. (Org.). Educação integral: ideário pedagógico, políticas e práticas. São Luís: Edufma, 2013.

LÜCK, H. Concepções e processos democráticos de gestão educacional. Rio de Janeiro: Vozes, 2006.

MAURÍCIO, L. V. Educação integral e(m) tempo integral na educação infantil: possibilidade de um olhar inovador. In: ARAÚJO, V. C. de (Org.). Educação infantil em jornada de tempo integral: dilemas e perspectivas. Brasília, DF: MEC; Vitória, ES: EDUFES, 2015.

PALMEN, S. H. C. A especificidade da gestão na educação infantil. Revista Pátio: Educação Infantil, ano 13, n. 43, abr./ jun. 2015.

PARO, V. H. Diretor escolar: educador ou gerente? São Paulo: Cortez, 2015.

PEIXOTO, E. M.; SCHUCHTER, T. M.; ARAÚJO, V. C. O tempo integral na educação infantil: financiamento, gestão e projeto político-pedagógico em questão. In: ARAÚJO, V. C. (Org.). Educação infantil em jornada de tempo integral: dilemas e perspectivas. Brasília, DF: MEC; Vitória, ES: EDUFES, 2015.

PIMENTEL, A. Vygotsky: uma abordagem histórico-cultural da educação infantil. In: FORMOSINHO-OLIVEIRA, J. O.; KISHIMOTO, T. M.; PINAZZA, M. A. Pedagogias da infância: dialogando com o passado, construindo o futuro. Porto Alegre: Artmed, 2007.

SARMENTO, M. J. Para uma agenda da educação da infância em tempo integral assente nos direitos da criança. In: ARAÚJO, V. C. de (Org.). Educação infantil em jornada de tempo integral: dilemas e perspectivas. Brasília, DF: MEC; Vitória, ES: EDUFES, 2015.

VALVERDE, S. L. As múltiplas linguagens: encorajar a ler. In: FARIA, A. L. G. de; MELLO, S. A. (Org.). Territórios da infância: linguagens, tempos e relações para uma pedagogia para as crianças pequenas. 2. ed. Araraquara, SP: Junqueira \& Marin, 2009.

ZABALZA, M. A.; CERDEIRINÃ, M. A. Z. A escola infantil como contexto de vida e de aprendizagens. Revista Pátio: Educação Infantil, ano 13, n. 43, abr./jun. 2015. 